\title{
The Future is Here: Precision Genome Editing for the Treatment of Blood and Immune Disorders
}

\author{
Ward AC* \\ School of Medicine, Deakin University, Australia \\ *Corresponding author: Alister C. Ward, School of \\ Medicine, Deakin University, Geelong, Victoria 3216, \\ Australia
}

Received: March 14, 2017; Accepted: March 20, 2017; Published: March 24, 2017

\section{Editorial}

Ever since the realization that many important diseases had an underlying genetic basis, the idea of using genetic modifications to treat them has been a holy grail of clinical medicine, especially for the array of monogenic diseases caused by small genetic changes. Such an approach has been seen as particularly attractive for blood and immune disorders due to the accessibility of these cells and the advances made in their in vitro manipulation and propagation. However, the very low efficiencies of specific gene targeting have resulted in a reliance on viral vectors to drive expression of transgenes. Such methodologies have had mixed success, with unintended pathogenic outcomes caused by immune responses to the virus and inappropriate gene activation in some cases.

Precision genome editing has emerged from a basic research curiosity to a powerful and sophisticated approach with wide applications across biology, biotechnology, agriculture and medicine [1-4], including for the treatment of blood and immune disorders [5]. Precision genome editing describes a series of technologies that allow the modification of genes and genomes in a highly specific and efficient manner, based on either Zinc Finger Nucleases (ZFNs), Transcription Activator-Like Effectors Nucleases (TALENs) or Clustered Regularly Interspaced Short Palindromic Repeats (CRISPR)/CRISPR-associated 9 (Cas9) [6].

ZFNs and TALENs act as artificial restriction enzymes. Each consists of an array of sequence-specific DNA-binding domains - based on either zinc finger domains that recognize a specific nucleotide triplet [7] or Tal repeats that recognize single nucleotides [8], respectively - fused to a non-specific nuclease domain, typically based on FokI that cuts the DNA [9]. The CRISPR/Cas9 system instead uses complementary base pairing between a 'guide' RNA and the target sequence that is recognized by the Cas9 nuclease that cleaves at an adjacent site [10]. The cleaved genomic DNA in each case is subsequently repaired through native repair processes [6] These include Non-Homologous End Joining (NHEJ) and Micro Homology-Mediated End Joining (MHMEJ) that occur in the absence of any repair template, resulting in the efficient introduction of insertion/deletion mutations which typically result in ablation of gene function [11,12]. In contrast, Homology-Dependent Repair (HDR) uses a donor template with homology to the cleavage site to introduce specific genetic alterations - including entire genes - in an efficient manner [13].
The first successful precision genome editing applied to humans was the modification of $\mathrm{CD} 4^{+} \mathrm{T}$ cells isolated from HIVinfected patients. The isolated $\mathrm{T}$ cells were targeted with ZFNs to introduce a naturally-occurring mutation in the CCR5 gene that confers resistance to HIV infection. These cells were expanded and reintroduced into the patients, around $50 \%$ of whom were able to stop antiretroviral medication [14]. The second report used TALENs to target TCR $\alpha$ and CD52 in non-human T cells to enable their safe transfusion into a recipient $\mathrm{B}$ cell acute lymphoblastic leukemia patient who subsequently went into remission [15]. Another group has used CRISPR/Cas9 to disable the PD1 gene in patient T cells, thereby removing its inhibitory effect on the tumor killing ability of these cells [16], with this approach currently being tested in patients with non-small cell lung cancer [17]. Other studies are extending this technology to replace defective genes: for example, introducing the gene encoding Factor IX into the albumin gene in monkeys [18], or resurrecting non-functional pseudo genes to correct p47phoxdeficient chronic granulomatous disease in patient cells [19].

While these approaches have raised ethical concerns, the focus on targeting somatic cells has been seen as acceptable. However, two separate groups of Chinese scientists have successfully edited (non-viable) human embryos with CRISPR/Cas9: one correcting a $\beta$-thalassemia causing mutation in the $H B B$ gene [20], the other introducing the CCR5 variant associated with HIV resistance [21]. This work has recently been extended to normal human zygotes, where point mutations in $H B B$ and G6PD were corrected with this technology [22]. This raises the possibility of germline transmission, which elevates the ethical stakes considerably. In such settings the advice to 'make haste, slowly' seems especially prudent.

\section{References}

1. Carlson DF, Tan W, Hackett PB, Fahrenkrug SC. Editing livestock genomes with site-specific nucleases. Reprod Fertil Dev. 2013; 26: 74-82.

2. Sertori R, Trengove MC, Basheer F, Ward AC, Liongue C. Genome editing in zebrafish: a practical overview. Brief Func Genom. 2016; 15: 322-330.

3. Schneller JL, Lee CM, Bao G, Venditti CP. Genome editing for inborn errors of metabolism: advancing towards the clinic. BMC Med. 2017; 15: 43.

4. Zhang K, Raboanatahiry N, Zhu B, Li M. Progress in genome editing technology and its application in plants. Front Plant Sci. 2017; 8: 177.

5. Kohn DB, Kuo CY. New frontiers in the therapy of primary immunodeficiency: From gene addition to gene editing. J Allergy Clin Immunol. 2017; 139: 726732.

6. Gaj T, Gersbach CA, Barbas III CF. ZFN, TALEN, and CRISPR/Cas-based methods for genome engineering. Trends Biotech. 2013; 31: 397-405.

7. Urnov FD, Rebar EJ, Holmes MC, Zhang HS, Gregory PD. Genome editing with engineered zinc finger nucleases. Nat Rev Genet. 2010; 11: 636-646.

8. Bogdanove AJ, Voytas DF. TAL effectors: customizable proteins for DNA targeting. Science. 2011; 333: 1843-1846.

9. Wood AJ, Lo TW, Zeitler B, Pickle CS, Ralston EJ, Lee AH, et al. Targeted 
genome editing across species using ZFNs and TALENs. Science. 2011; 333: 307.

10. Ran FA, Hsu PD, Wright J, Agarwala V, Scott DA, Zhang F. Genome engineering using the CRISPR-Cas9 system. Nat Protoc. 2013; 8: 2281 2308.

11. Pingoud A, Silva GH. Precision genome surgery. Nat Biotechnol. 2007; 25 743-744

12. McVey M, Lee SE. MMEJ repair of double-strand breaks (director's cut) deleted sequences and alternative endings. Trends Genet. 2008; 24: 529538 .

13. Hartlerode AJ, Scully R. Mechanisms of double-strand break repair in somatic mammalian cells. Biochem J. 2009; 423: 157-168.

14. Tebas P, Stein D, Tang WW, Frank I, Wang SQ, Lee G, et al. Gene editing of CCR5 in autologous CD4 T cells of persons infected with HIV. N Engl J Med. 2014; 370: 901-110.

15. Qasim W, Zhan H, Samarasinghe S, Adams S, Amrolia P, Stafford S, et al Molecular remission of infant B-ALL after infusion of universal TALEN geneedited CAR T cells. Sci TransI Med. 2017; 9.

16. Su S, Hu B, Shao J, Shen B, Du J, Du Y, et al. CRISPR-Cas9 mediated efficient PD-1 disruption on human primary $\mathrm{T}$ cells from cancer patients. Sci Rep. 2016; 6: 20070.
17. Cyranoski D. CRISPR gene-editing tested in a person for the first time. Nature. 2016; 539: 479

18. Sharma R, Anguela XM, Doyon Y, Wechsler T, DeKelver RC, Sproul S, et al. In vivo genome editing of the albumin locus as a platform for protein replacement therapy. Blood. 2015; 126: 1777-1784

19. Merling RK, Kuhns D, Sweeney CL, Wu X, Burkett S, Chu J, et al. Gene-edited pseudogene resurrection corrects p47phox-deficient chronic granulomatous disease. Blood Adv. 2017; 1: 270-278.

20. Liang $P, X u ~ Y$, Zhang $X$, Ding C, Huang R, Zhang Z, et al. CRISPR/Cas9mediated gene editing in human tripronuclear zygotes. Protein Cell. 2015; 6: $363-372$

21. Kang $X$, He W, Huang $Y, Y u$ Q, Chen $Y$, Gao X, et al. Introducing precise genetic modifications into human 3PN embryos by CRISPR/Cas-mediated genome editing. J Assist Reprod Genet. 2016; 33: 581-588.

22. Tang L, Zeng $Y$, Du H, Gong M, Peng J, Zhang B, et al. CRISPR/Cas9mediated gene editing in human zygotes using Cas9 protein. Mol Genet Genomics. 2017.
J Blood Disord - Volume 4 Issue 1 - 2017

ISSN 2379-8009 | www.austinpublishinggroup.com

Ward. (C) All rights are reserved
Citation: Ward AC. The Future is Here: Precision Genome Editing for the Treatment of Blood and Immune Disorders. J Blood Disord. 2017; 4(1): 1042. 